\title{
Retraction Note: Overestimated accuracy of circular dichroism in determining protein secondary structure
}

\author{
Kailei Lin $\cdot$ Huayan Yang $\cdot$ Zhengya Gao $\cdot$ \\ Feng Li $\cdot$ Shaoning Yu
}

Published online: 14 March 2014

(C) European Biophysical Societies' Association 2014

\section{Retraction Note: Eur Biophys J (2013) 42:455-461 \\ DOI 10.1007/s00249-013-0896-y}

After publication of this article, concerns were raised regarding accuracy and interpretation of the presented Circular Dichroism data. To investigate these claims, the article was checked again by two additional referees, and was also discussed by members of the European Circular Dichroism Society. The investigation revealed that the Circular Dichroism aspects of the article are invalid, because the measured protein Circular Dichroism spectra are highly inaccurate, and contradict numerous published studies. Hence, the conclusions of the authors regarding the unreliability of using Circular Dichroism for protein secondary structure determination are unjustified and misleading. When confronted with these findings, the authors were unable to dispel the doubts in their experimental methods and declined the invitation to withdraw the article themselves. It could also not be clarified, why the Circular Dichroism spectra presented in this paper have anomalously low amplitudes.

As a result of these findings and the subsequent discussions, the Managing Editor of the European Biophysics Journal, Anthony Watts, has now retracted this article.

The online version of the original article can be found under doi:10.1007/s00249-013-0896-y.

K. Lin $\cdot$ H. Yang $\cdot$ Z. Gao $\cdot$ F. Li $\cdot$ S. Yu ( $\bowtie)$

Department of Chemistry, Fudan University,

Shanghai 200433, China

e-mail: yushaoning@fudan.edu.cn 